\title{
Real-Time Prediction of the Wind Power Based on Improved Sustainable Model
}

\author{
Mao Yang \\ School of electrical engineering, \\ Northeast DianLi University \\ Jilin, China \\ e-mail: yangmao820@163.com
}

\author{
Yunpeng Jia \\ School of electrical engineering, \\ Northeast DianLi University \\ Jilin, China \\ e-mail:wcnm199107@126.com
}

\begin{abstract}
Accurate prediction of wind power is an effective technology to achieve the large-scale utilization of wind energy. This article conducts in-depth research on real-time prediction of wind power based on the interim measures for the management of power prediction and prediction of wind farm published by the National Energy Board. It begins with an analysis of several typical prediction methods on single step, and gives the recommended modeling domain length, and puts forward the improved sustainable model which combines a time series model with sustainable model. We conduct several real-time predictions under different conditions with the data of wind power measured in a wind farm in Northeast China, evaluate different models combined with the corresponding marks in the files published by the National Energy Board. It proves that the improved sustainable method can improve the accuracy of prediction effectively.
\end{abstract}

Keywords: time series models; sustainable model; real-time prediction; evaluation of prediction

\section{INTRODUCTION}

Wind energy as a $\mathrm{r}$ enewable clean energy plays an increasingly important role in today's life. Turn wind energy into electricity grid can reduce the $p$ ollution of the environment and to a c ertain extent ease the world energy crisis today $[1,2]$. When wind generation is significant in a power system, wind power prediction becomes an important factor in defi ning the operation planning policies $t o$ be adopted by a transmission system operator (TSO), namely in accepting high wind penetration $[3,4,5]$.

The prediction of power output from a wind park is highly important presently in Euro pe, where the growing penetration of wind gener ation has reached heavy percentages (in the range of $5 \%$ to $20 \%$ ) in some countries in recent years, like Germany, Spain, Denmark, or other, and increases in these values are co mmon targets for energy policies defined [6,7]. For instance, in Portugal by 2010, some $5100 \mathrm{MW}$ of wind generators will be installed, when country peak power consumption is about $8500 \mathrm{MW}$ in 2008 . So, we are no longer talking of marginal effects $[8,9,10]$.

According to preliminary statistics, China's new wind power installed capacity was close to 18 million kilowatts in 2011 , total installed capacity reached $65 \mathrm{~m}$ illion kilowatts $[11,12]$. China is al ready the world's superpower in win $d$ power equipment manufacturing and the largest country in the wind power installed capacity. But the near ground wind has features such as volatility, intermittent, low energy density and so on, makes accurate prediction of wind power becoming a big problem [13]. Therefore, to improve the prediction accuracy of wind power has become the primary task. Accurate prediction of wind power, in favor of wind power connecting to the electricity grid, making reasonable arrangement of dispatching plan, reducing the influence of fluctuation of wind power grid, ensuring the safety of power grid running smoothly, increasing the ability of wind power bidding online.

Foreign advanced prediction method using numerical weather prediction model to predict effectively, such as Denmark Prediktor prediction system and Spain LocalPred prediction system have both achieved good effect [14].

Domestic wind power has a variety of prediction methods, including the BP neural network, time series ARMA model, linear regression, sustainable prediction method and combined prediction method and so on, these methods in one step pred iction precision is higher. But the accuracy is low in multi-step real-time prediction, also can not exceed the conservative ideas of sustainable prediction model [15].

This article starts from the requirements of improving prediction accuracy of wind power, combines sustainable method with time series model innovatively, constructs sustainable prediction model. This article has chosen the actual power of a wind generating set as the historical data in Northeast China from May 102006 to May 20 2006, we use the real-time wind power pr ediction under different time scales from midnight on May 20 an d combine with the national energy bureau issued "interim measures for wind farm power prediction management" to analyze the results of evaluation index. Prediction results show that the improved sustainable prediction model can effectively improve the prediction precision.

\section{PRACTICAL APPLICATION SitUATION}

\section{A. Wind Farm Situation}

This article adopts the wind farm which is composed of 58 wind turbines, the rated out put power of every unit is $850 \mathrm{kw}$. Specifies that the four wind turbines of the wind farm (A, B, C, D), the data of output power (denoted as PA, $\mathrm{PB}, \mathrm{PC}, \mathrm{PD}$ ); The total power output of four sets is denoted as $\mathrm{P} 4$ and the total output data of 58 wind turbines (denoted as P58). 
On the basis of the electric power dispatching department for the different needs of op eration mode, wind power prediction is divided into day pr ediction and real-time prediction. Day prediction is to point to predict the future 24 hours at 96 time points of the wind power value. The realtime prediction refers to use every time point to predict future 4 hours at 16 ti me points of the wind po wer value. This paper mainly studies the real-time prediction and applies A table wind power generating unit as the main research object.

\section{B. Evaluation}

In this pa per, the evaluation of real-time prediction of wind power is based on the prediction assessment indicators of grid wind farms from national energy administration, as follows:

Accuracy:

$$
r_{1}=\left[1-\sqrt{\frac{1}{N} \sum_{k=1}^{N}\left(\frac{P_{M K}-P_{P K}}{C a p}\right)^{2}}\right] \times 100 \%
$$

In which, $r_{1}$ is prediction planning curve accuracy; $P_{M K}$ is the average value of the actual power of $\mathrm{K}$ ti mes; $P_{P K}$ is the average value of prediction power of K times; $\mathrm{N}$ is the total numbers of such periods of the day assessment (about 96 points - from the inspection); Cap is boot capacity of wind farms.

Qualified rate:

$$
r_{2}=\frac{1}{N} \sum_{K=1}^{N} B_{K} \times 100 \%
$$

In which,

$$
\begin{aligned}
& \left(1-\frac{P_{M K}-P_{P K}}{\operatorname{Cap}}\right) \times 100 \% \geq 85 \%, B_{K}=1, \\
& \left(1-\frac{P_{M K}-P_{P K}}{\operatorname{Cap}}\right) \times 100 \%<85 \%, B_{K}=0 .
\end{aligned}
$$

RMS error:

$$
r_{3}=\sqrt{\frac{\sum_{k=1}^{N}\left(\frac{P_{M K}-P_{P K}}{C a p}\right)^{2}}{N-1}} \times 100 \%
$$

Document [1] requires the error of real-time prediction of the grid wind power should be less than $15 \%$, the RMS error of predicted results should be less than $20 \%$ throughout the day.

\section{Classical PRediction Model InTROdUction AND ANALYSIS OF THE RESULTS}

\section{A. Time Series Models}

Time series data with time advancing have a certain correlation between each other, prediction model is established depending on the correlation of data variables before and a fter and the distribution of the random disturbance item. Time series application flow chart as shown in Fig.1.

Implementing stationarity test on the raw data of A unit, finds the data do not meet the stability requirements, after the first-order differential to the data, gains test results as shown in Fig.2, the ADF has a value of -25.35358 is less than 3.438672. So we have $99 \%$ certaint $y$ that the data has reached smoothly.

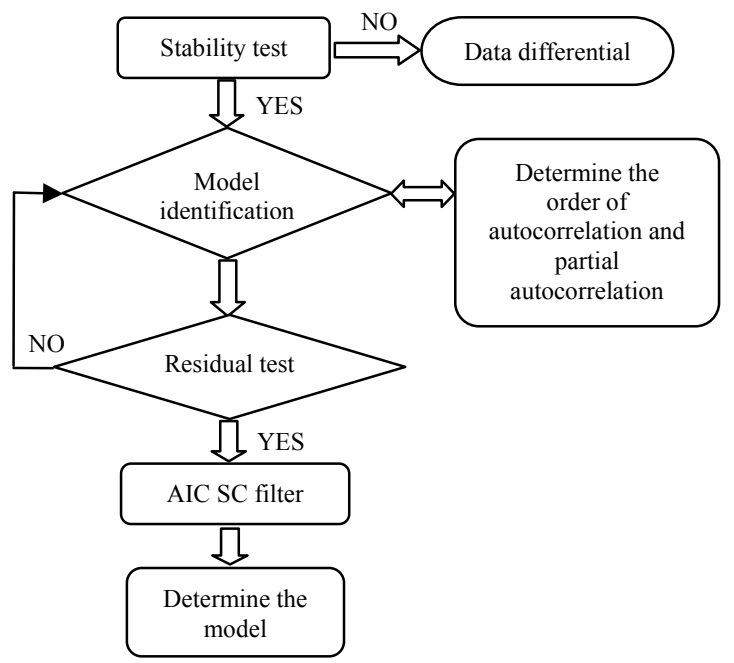

Figure 1. ARMA MODEL'S FOUNDATION PROCESS

\section{Null Hypothesis: D(Z) has a unit root}

Exogenous: Constant

Lag Length: 1 (Automatic based on SIC, MAXLAG=19)

\begin{tabular}{lccc}
\hline \hline & t-Statistic & Prob. \\
\hline \hline Augmented Dickey-Fuller test statistic & -25.35358 & 0.0000 \\
\hline Test critical values: $\quad$ 1\% level & -3.438672 & \\
& $5 \%$ level & -2.865103 & \\
& 10\% level & -2.568722 & \\
\hline
\end{tabular}

*Mackinnon (1996) one-sided p-values.

Figure 2. THE RESULt OF FIRST DIFFERENCE 


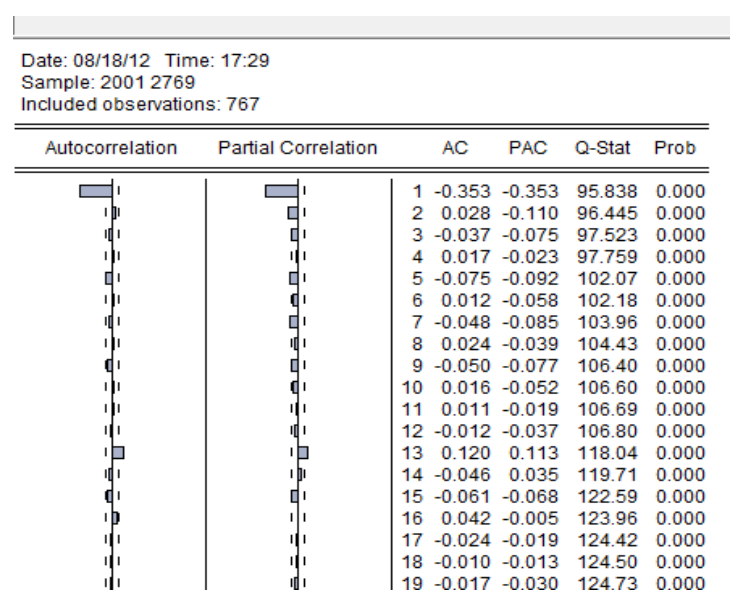

Figure 3. MODEL'S RECOGNIZING

TABLE I. EXAMINATION SHEET OF AIC SC

\begin{tabular}{cccc}
\hline $\begin{array}{c}\text { Detection } \\
\text { value }\end{array}$ & ARI (1,1) & ARI (2,1) & $\begin{array}{c}\text { ARIMA } \\
(\mathbf{3 , 1 , 0})\end{array}$ \\
\hline AIC & 13.049 & 13.083 & 13.105 \\
\hline$S C$ & 13.021 & 13.029 & 13.023
\end{tabular}

By Fig.3, we can determine the order number is 3 from the autocorrelation coefficient and the partial autocorrelation coefficient, make AIC and SC test on ARI(1) and ARI(2). Test results are shown in Tab.1, we ca $\mathrm{n}$ conclude that $\operatorname{ARIMA}(3,1,0)$ is the final model.

\section{B. Linear Regression Model}

Linear regression is a kind of prediction method that tends to causal analysis. So take advantage of the correlation analysis of historical data of wind power to predict, the stationarity of historical data and the modeling domain length of the linear regression model are greatly affecting the precision of the prediction.

As a result, the li near regression model application flow chart as shown in Fig.4.

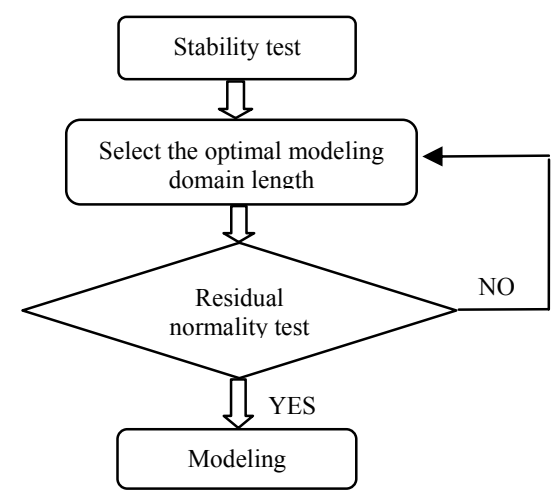

Figure 4. LINEAR REGRESSION MODEL's FOUNDATION PROCESS
The following to explore the relationship between the step length selection of $\mathrm{t}$ he modeling domain and the precision, as shown below.

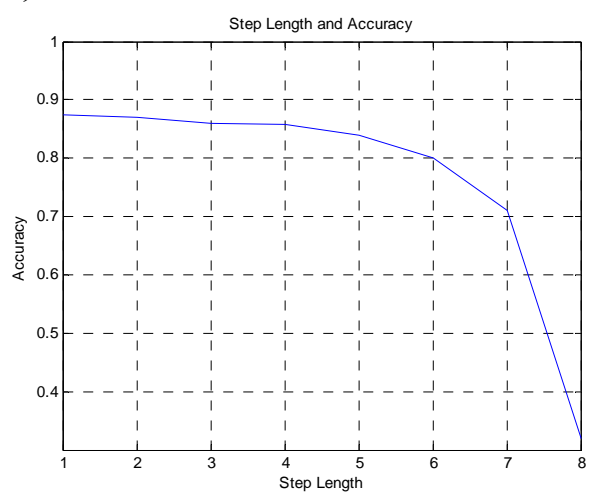

Figure 5. STEP LENGTH - ACCURACY PROFILE

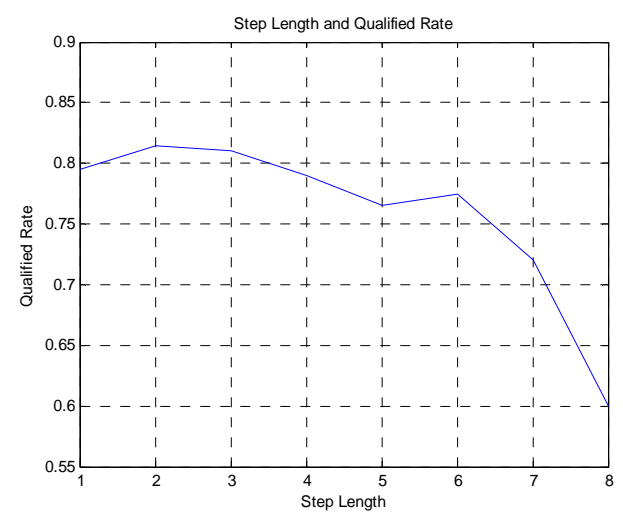

Figure 6. STEP LENGTH - QUALIFIEd RATE PROFILE

You can see from figure, the accuracy rate and the qualified rate of prediction show a trend of decreasing with the increase of length of modeling domains. Therefore, let the length of the modeling domain be 2 .

\section{Sustainable Model}

Sustainable prediction is to make the actual value of prediction time point in historical data as one or a set of predicted values. In multi-step prediction, the prediction trend will not change as prediction waveform change. To ensure that the error will not scroll with data accumulated step by step.

The sustainable model is more widely used in the wind power prediction, the method is simple and has high precision, has become the benchmark for the pros and cons of prediction methods of wi nd power. Makes real-time prediction of wind power for A unit at each time point in the May 20, lets the actual value of wind power of the time point as the predi ctive values of the nex $t 16$ points in time, accuracy analysis as shown in Tab.2.

\section{Combination Prediction Model}

The combination prediction model uses the information provided by each individual model, uses an app ropriate 
method to assign weights, weighted average to the predictive value of a single model, than derives the predictive value, makes model get higher prediction accuracy.

There are several ways to de termine the weights of the combination prediction, this article uses cooperative game method which is from the point of view of game theory, depending on the i ndividual prediction methods for the players of combination prediction, the "results" of cooperation for the sum of squared errors of the combination prediction, the individual prediction model is all ocated in accordance with the cooperative game Shapley V alue method, to obtain the weights of combination prediction. Following we can see the time series $\operatorname{ARIMA}(3,1,0)$ model, the linear regression model and the sustainable model portfolio prediction accuracy in Tab.2.

TABLE II. THE COMPARATION OF FOUR TYPICAL MODELS PRECISION

\begin{tabular}{ccccc}
\hline Model & Period & $\begin{array}{c}\text { Accuracy } \\
(\%)\end{array}$ & $\begin{array}{c}\text { Qualified } \\
\text { rate (\%) }\end{array}$ & $\begin{array}{c}\text { RMS } \\
\text { error (\%) }\end{array}$ \\
\hline $\begin{array}{c}\text { ARIMA } \\
\mathbf{( 3 , 1 , 0 )} \\
\text { model }\end{array}$ & Once & 77.885 & 43.750 & 22.840 \\
\hline $\begin{array}{c}\text { Linear } \\
\text { regression } \\
\text { model }\end{array}$ & Once & 84.933 & 68.750 & 15.561 \\
\hline $\begin{array}{c}\text { One day } \\
\text { mostainable }\end{array}$ & Once & 76.963 & 72.223 & 13.465 \\
\hline $\begin{array}{c}\text { model } \\
\text { Combinatio } \\
\text { n model }\end{array}$ & One day & 87.649 & 72.809 & 12.757 \\
\hline One day & 87.785 & 74.678 & 12.616 \\
\hline
\end{tabular}

Tab.2 shows that under the same conditions as wind power prediction, single prediction can not evaluate the precision of the model is good or bad, but day prediction is more reasonable, ARIMA $(3,1,0)$ model and the combination prediction model have higher accuracy.

\section{IMPROVED SUSTAINABLE MODEL}

\section{A. Improved Sustainable Prediction Model Principle}

The sustainable model directly uses the actual value as predictive value, can avoid the prediction error into the back of the rolling prediction because of recursive prediction, but it is difficult to express the trend of the time data in the future, also considers using historical data to predict only one point has been very mature, has higher precision and be able to reflect the change trend of the future moments better. AR model just can take the correlation between the data into account; coincide with the strong correlation of wind power prediction in a s hort period of time. Thus, we pr opose improved sustainable model combined the AR model with the sustainable model and make one-step predictive values of the AR model as the real-time prediction predictive values of 16 time points.

\section{B. Improved Sustainable Predict Case Study}

The prediction accuracy of the $\operatorname{ARIMA}(3,1,0)$ model is the highest seen by the above time series models, therefore, we get $\operatorname{ARIMA}(3,1,0)$ improved sustainable method, $\operatorname{ARIMA}(3,1,0)$ model obtains the prediction power value from the historical data before the predicted point and makes it as a real-time prediction predictive value of 16 points in 4 hours. Real-time prediction for one da y of 96 times prediction, every prediction establishes an AR model, can obtain the e valuations such as the acc uracy, the qualified rate and the RMS error in every time and in one day and so on.

1) Accuracy comparison between improved sustainable model with $\operatorname{ARIMA}(3,1,0)$ model and the sustainable method.

Compare the evaluations in one time prediction and in one day prediction using improved sustainable method such as Tab. 3 and Tab.4.

TABLE III. THE COMPARATION OF IMPROVING SUSTAINABLE MODEL AND ARIMA $(3,1,0)$ MODEL'S PRECISION

\begin{tabular}{cccc}
\hline Model & $\begin{array}{c}\text { Accuracy } \\
(\%)\end{array}$ & $\begin{array}{c}\text { Qualified rate } \\
(\%)\end{array}$ & $\begin{array}{c}\text { RMS error } \\
(\%)\end{array}$ \\
\hline $\begin{array}{c}\text { ARIMA(3,1,0) } \\
\text { model }\end{array}$ & 94.290 & 100.000 & 5.897 \\
\hline $\begin{array}{c}\text { Improved } \\
\text { Sustainable } \\
\text { model }\end{array}$ & 95.241 & 100.000 \\
\hline
\end{tabular}

Figure 7. THE COMPARATION OF IMPROVING SUSTAINABLE MODEL AND ARIMA(3,1,0) MODEL'S PRECISION

TABLE IV. THE COMPARATION OF IMPROVING SUSTAINABLE MODEL AND SUSTAINED MODEL'S PRECISION

\begin{tabular}{cccc}
\hline Model & $\begin{array}{c}\text { Accuracy } \\
(\%)\end{array}$ & $\begin{array}{c}\text { Qualified rate } \\
(\%)\end{array}$ & $\begin{array}{c}\text { RMS error } \\
(\%)\end{array}$ \\
\hline $\begin{array}{c}\text { Sustainable } \\
\text { model }\end{array}$ & 87.649 & 72.809 & 12.757 \\
\hline $\begin{array}{c}\text { Improved } \\
\text { sustainable } \\
\text { model }\end{array}$ & 88.101 & 76.16 & 12.289 \\
\hline \begin{tabular}{c} 
Seen from \\
\hline
\end{tabular} & & & \\
\hline
\end{tabular}

Seen from Tab.3 and Fig.7, improved sustainable model avoids the second-stage prediction error of the $\operatorname{ARIMA}(3,1,0)$ model, improves the prediction precision. 
2) The accuracy analysis of improved sustainable model under different conditions.

In order to av oid the impact of causal factors, we take power data from the $\mathrm{B}, \mathrm{C}, \mathrm{D}$ unit, 4 units and 58 units $\mathrm{t} \mathrm{o}$ validate the one-day prediction accuracy of improved sustainable method under different operating conditions.

TABLE V. THE COMPARATION OF IMPROVING SUSTAINABLE MODEL AND SUSTAINED MODEL'S PRECISION OF GENERATOR B

\begin{tabular}{cccc}
\hline Model & $\begin{array}{c}\text { Accuracy } \\
(\%)\end{array}$ & $\begin{array}{c}\text { Qualified rate } \\
(\%)\end{array}$ & $\begin{array}{c}\text { RMS error } \\
(\%)\end{array}$ \\
\hline $\begin{array}{c}\text { Sustainable } \\
\text { model }\end{array}$ & 87.043 & 74.936 & 13.382 \\
\hline $\begin{array}{c}\text { Improved } \\
\text { sustainable } \\
\text { model }\end{array}$ & 87.474 & 75.322 & 12.937 \\
\hline
\end{tabular}

TABLE VI. THE COMPARATION OF IMPROVING SUSTAINABLE MODEL AND SUSTAINED MODEL'S PRECISION OF 4 GENERATORS

\begin{tabular}{cccc}
\hline Model & $\begin{array}{c}\text { Accuracy } \\
(\%)\end{array}$ & $\begin{array}{c}\text { Qualified rate } \\
(\%)\end{array}$ & $\begin{array}{c}\text { RMS error } \\
(\%)\end{array}$ \\
\hline $\begin{array}{c}\text { Sustainable } \\
\text { model }\end{array}$ & 88.654 & 78.351 & 11.718 \\
\hline $\begin{array}{c}\text { Improved } \\
\text { sustainable } \\
\text { model }\end{array}$ & 89.014 & 80.284 & 11.346 \\
\hline
\end{tabular}

TABLE VII. THE COMPARATION OF IMPROVING SUSTAINABLE MODEL AND SUSTAINED MODEL'S PRECISION OF 58 GENERATORS

\begin{tabular}{cccc}
\hline Model & $\begin{array}{c}\text { Accuracy } \\
(\%)\end{array}$ & $\begin{array}{c}\text { Qualified } \\
\text { rate }(\%)\end{array}$ & RMS error (\%) \\
\hline $\begin{array}{c}\text { Sustainable } \\
\text { model }\end{array}$ & 91.934 & 85.052 & 8.330 \\
\hline $\begin{array}{c}\text { Improved } \\
\text { sustainable } \\
\text { model }\end{array}$ & 91.975 & 85.954 & 8.288 \\
\hline
\end{tabular}

From the above tables shows tha $t$ the accuracy of improved sustainable method is higher than the sustainable method under different conditions, which can effectively improve the accuracy of real-time prediction of wind power.

\section{CONCLUSION}

The article proposes improved sustainable method which is based on the higher precision characteristics of sustainable model in the multi-step real-time prediction of the wind power, and it is validated that improves the accuracy of realtime prediction effectively under different operating conditions. National Energy Board documents wind farm power prediction assessment indicators for the standard, accuracy is about $0.4 \%$ higher than the sustainable method and the qualified rate is about $1.2 \%$ higher. It has a strong practical value.
In the field of wind power prediction, there are still many problems waiting to be solved, such as the increase in prediction accuracy of wind power can not be unl imited, if not, how much the increase of the maximum critical limits can be, what factors influence these issues in turn and so on? In subsequent studies, we will have a targeted research in the accuracy ceiling of wind power prediction.

\section{ACKNOWLEDGMENT}

This research is supported by the National Program on Key Basic Research Project (973 Program) of China (Grant No.2013CB228201), all support is gratefully acknowledged.

\section{REFERENCES}

[1] R. Bakker, J. C. Schouten, C. L. Giles, F. Takens, and C. M. van den Bleek, Learning of chaotic attractors by neural networks, Neural Computation 12 (2000), no. 10, 2355-2383.

[2] C. Diks, W. R. van Zwet, F. Takens, and J. DeGoede, Detecting differences between delay vector distributions, Physical Review E 53 (1996), no. 3, 2169-2176.

[3] J. D. Far mer and J. J. Sidorowich, Predicting chaotic time series, Physical Review Letters 59 (1987), no. 8, 845-848.

[4] L. C. Giles, , S. Lawrence, and A. H. Tsoi, Noisy time series prediction using a recurrent ne ural network and grammatical inference, Machine Learning 44 (2001), no. 1/2, 161-183.

[5] K. Hornik, Multilayer feedforward networks are universal approximators, Neural Networks 2 (1989), 359-366.

[6] C. Igel and M. Husken, Improving the Rprop learning algorithm, Proceedings of the Second International ICSC Symposium on Neural Computation (NC 2000) (H. Bothe and R. Roja s, eds.), ICSC Academic Press, 2000, pp. 115-121.

[7] M. B. Kennel, R. Brown, and H. D. Abarbanel, Determining embedding dimension for phase-space reconstruction using a geometrical construction, Physical Review A 45 (1992), no. 6, 34033411 .

[8] G.D. Magoulas, V.P. Plagianakos, and M .N. Vrahatis, Adaptive stepsize algorithms for on-line training of neural networks, Nonlinear Analysis, T.M.A. 47 (2001), no. 5, 3425-3430.

[9] G.D. Magoulas, M.N. Vrahatis, and G.S. Androulakis, Effective backpropagation training with variable stepsize, Neural Networks 10 (1997), no. 1, 69-82.

[10] T. P. Meyer and N. H. Packard, Local forecasting of high dimensional chaotic dynamics, Nonlinear Modelling and Forecasting (M. Casdagli and S. Eubank, eds.), Addison-Wesley, 1992, pp. 249-264.

[11] M. Moller, A scaled conjugate gradient algorithm for fast supervised learning, Neural Networks 6 (1993), 525-533.

[12] N. G. Pavlidis, D. K. Tasoulis, and M. N. Vrahatis, Financial forecasting through unsupervised clustering and evolutionary trained neural networks, Proceedings of the Congress on Evolutionary Computation (CEC 2003), 2003, pp. 2314-2321.

[13] A. Pinkus, Approximation theory of the M LP model in neural networks, Acta Numerica (1999), 143-195.

[14] J. C. Principe, A. Rathie, and J. M. Kuo, Prediction of chaotic time series with neural networks and the issue of dynamic modeling, Int. J. of Bifurcation and Chaos 2 (1992), no. 4, 989-996.

[15] J. C. Principe, L. Wang, and M. A. Motter, Local dynamic modeling with self-organizing maps and applications to nonlinear syste $\mathrm{m}$ identification and control, Proceedings of the IEEE, no. 6, 1998, pp. 2240-2257. 